\title{
Analysis of Aerobic Power and Swing Characteristics in Young Male Race Walkers
} \author{
Santiniketan, India \\ Email address: \\ bejdibendu127@gmail.com (D. K. Bej) \\ ${ }^{*}$ Corresponding author
}

Dibendu Kumar Bej ", Brajanath Kundu

Department of Physical Education \& Sports Science, Visva-Bharati (A Central University and an Institution of National Importance),

\section{To cite this article:}

Dibendu Kumar Bej, Brajanath Kundu. Analysis of Aerobic Power and Swing Characteristics in Young Male Race Walkers. American Journal of Sports Science. Vol. 8, No. 3, 2020, pp. 62-67. doi: 10.11648/j.ajss.20200803.13

Received: July 9, 2020; Accepted: July 22, 2020; Published: August 10, 2020

\begin{abstract}
Economical walking is defined by the steady state of oxygen consumption with top speed and technique in competition is one of the most important factors to achieve higher performance for Pedestrians. The technique of race walking which is defined by World Athletics race walking competitions rules 230.54.2 not a naturally obtained human skill as normal walking and running of childhood. The purpose of the study was to analyze the association and relation of race velocity with aerobic capacity and kinematic properties. Top 10 race walkers of $10000 \mathrm{~m}$ race walk discipline (Men- U 20), from $33^{\text {rd }}$ National Junior Athletic Championships, Nov, 2017 held at Acharya Nagarjuna University, Vijaywada, A. P. India were digitized as the subject. For kinematic analysis, athletes were recorded as they passed through halfway $4.55 \mathrm{KM}$ at back straight on the $400 \mathrm{~m}$ track by using two standard digital HD camcorders (Nikon B700,60Hz) mounted on rigid tripods $90^{\circ}$ angle $4 \mathrm{~m}$ away from the track inside \& outside where reference volume was $5 \mathrm{~m}$ long and $1.5 \mathrm{~m}$ high. Whereas to measure $\mathrm{Vo}_{2}$ Max athletes' performance were taken as they passed through 1.5 miles or $2414.02 \mathrm{~m}$ on the track. The video data were analyzed by using motion analysis software (KINOVEA). Descriptive statistics and Pearson Product Moment Correlation coefficient $(p<0.05)$ were employed for statistical calculation. The tabulation of data was done by using the IBM SPSS software. The result of the study showed that the correlation between race performance and $\mathrm{VO}_{2}$ max was quite high, $\mathrm{r}(8 \mathrm{df})=$ 0.726. A Strong relationship was found between step length and RW performance, i.e. $\mathrm{r}(8 \mathrm{df})=0.689$. Whereas variables like, flight time, linearity, maximum knee and foot height of swing leg were positively correlated with the walking performance. A high degree positive association was located in the torso and pelvic displacement $r=0.768 \& 0.804$ respectively. In toe off phase " $r$ " value of knee angle with performance was 0.742 that showed a high degree coefficient of correlation. Whereas at heel contact and mid stance phase a low degree negative correlation found $(\mathrm{r}=-0.489 \&-0.406)$. Most of the calculated " $\mathrm{r}$ " values were significant as the critical value of $8 \mathrm{df}$ at 0.05 level is 0.631 . Due to the direct association of race walking velocity (Mean $=3.427 \mathrm{~m} / \mathrm{s} \& \mathrm{SD}=$ 0.235) with $\mathrm{VO}_{2}$ max, step length, knee angle, torso \& pelvic displacement may be this type of result found indifferent phases. Race walking performance was positively associated with the race walking economy (kinematic and physiologic variables), which implies that the fastest race walkers were more economical than the lesser performers. In relation to RW technique and forward propulsion, displacement of torso and pelvic region observed a significant role.
\end{abstract}

Keywords: Heel Contact, Mid Stance, Pedestrian, Toe off, Kinematic, $\mathrm{VO}_{2} \mathrm{Max}$, etc.

\section{Introduction}

Economical walking is defined by the steady state of oxygen consumption with top speed and technique in competition is one of the most important factors to achieve higher performance for Pedestrians. The technique of race walking which is defined by Word Athletics Competitions
Rules [17] of race walking 230.54.2 is not a naturally obtained human skill as normal walking and running are obtained in childhood [13]. Race walking event requires utmost beauties in the skill part i.e. heel contact, mid stance and toe off of the advancing leg. Elite race walkers moved with a fluidity and grace that are the envy of anyone who has tried the low impact yet high intensity sport of race walking. 
Most economical race walkers may have distinct race walking patterns [4]. They capable of traveling in excess of 10 miles per hour; they zip along with rhythmic synchronicity [14]. Race walking is part of the athletics program at the Olympic Games and all other major athletics championships. Races for junior men and women (under 20 years of age) are held over $10000 \mathrm{~m}$. The IAAF World Race Walking Cup is a biennial event intended primarily as a team competition between IAAF member nations; however, athletes also compete as individuals. As nations are allowed up to five entries per senior race, the participating numbers are relatively high compared with the more prestigious World Championships and Olympic Games. While it is very useful to measure biomechanical and physiological variables across large groups of athletes, it is equally valuable to focus on performances of the very best athletes in understanding the determinants of fast race walking. In race walking, the single most important factor in competitive success is speed, although this is restricted by the two unique rules of race walking technique. At the most basic level, speed is determined by step, or strides, length and stride frequency. The position of the support foot in relation to the athlete's whole body center of mass is important in maintaining forward speed. A foot landing too far in front of the body at initial contact can cause too great a braking impulse [10]. The distance to the support foot at toe-off is important in generating adequate stride length and forward propulsion [8].

Unlike other endurance sports, race walking is governed by strict biomechanical rules, as athletes are not allowed to have any visible loss of contact with the ground and must maintain a straightened knee from the initial contact with the ground until the vertical upright position [17]. The result of this is a distinct gait pattern and the need of not only endurance capacity, but also a great technical ability to perform at elite level $[5,6]$. For example, non-peer reviewed evidence suggests that when race walking, the optimum foot position at initial contact is directly under the center of mass, as a foot ahead approaching zero would result in considerably reduced braking forces and, therefore, help maintain forward momentum [15]. This would lead to a subsequent reduction in step length, which contrasts with research suggesting that larger step lengths would contribute to faster race walking speeds in elite race walkers [7, 9]. Other researchers have reported smaller vertical oscillations and longer flight times as key factors for increased walking speeds [4]. Success in race walking is related more to the efficiency of technique rather than physiological factors [8]. The correction and optimization of technique is therefore of great importance. Modifications in gait patterns may affect the energy cost of walking and these modifications can be caused by fatigue [1]. When the body is placed under immense physical pressure in endurance events such as race walking, performance can deteriorate due to the effects of fatigue. Athletes can normally continue performing whilst experiencing fatigue but their technique may alter [1]. These changes usually occur at the end of a race or within the final stages, when the final outcome is decided. This is especially important in race walking, where poor technique can lead to disqualification. In order for athletes to improve their overall performance, knowledge of when their technique starts to change and ways to combat changes may help prevent technique deterioration. A theoretical framework of which variables are most important to race walking success can then be considered and used by athletes and coaches to highlight indicators of success and relevant strengths and weaknesses.

\section{Objective}

The purpose of this study was to analyze and investigate the association and relation of kinematic and physiologic properties with the race walking performance. There were two objectives towards achieving this aim;

a) To measure the aerobic capacity $\left(\mathrm{VO}_{2} \max \right)$ as a physiologic parameter as to locate the association and significance with race walking (RW) performance.

b) To find out the associations of performance within the important kinematic (linear and angular) variables that can suggest the methods to improve performance.

\section{Methodology}

\subsection{Subjects}

From $33^{\text {rd }}$ National Junior Athletic Championships, 10000 $\mathrm{m}$ race walk discipline (Acharya Nagarjuna University, Vijaywada, A. P. India, 2017) top 10 (mean \pm SD; age $=19.2$ \pm 0.79 years; height $=172.6 \pm 8.5 \mathrm{~cm}$.) junior boys race walkers of U-20 age group were recorded and analyzed as a subjects of the study.

\subsection{Criterion Measures}

Table 1. Details of selected kinematic and physiologic variables.

\begin{tabular}{ll}
\hline Correlations & Measure \\
\hline Criterion & \\
\hline Physiological Parameter & $\mathrm{ml} / \mathrm{kg} / \mathrm{min}$ \\
$\mathrm{VO}_{2}$ Max (Larsen GE, $\mathrm{VO}_{2}$ Max Prediction Equation, 2002) & \\
Kinematic Parameter Linear Kinematics $^{12}$ & $\mathrm{~m} / \mathrm{s}$ \\
Velocity & Centimeter \\
Stride length & Centimeter \\
Flight distance & Sec. \\
Flight time & Centimeter \\
Torso displacement & Centimeter \\
Pelvic displacement & Centimeter \\
Maximum foot height of swing leg & Centimeter \\
Maximum knee height of swing leg & \\
Angular kinematics & Degree \\
Knee angel & \\
\hline
\end{tabular}

Definitions of specific reference points used in this study are as follows:

Initial contact: The first visible point during stance where the athlete's foot clearly contacts the ground.

Mid-stance: The point where the athlete's foot was directly below the body's center of mass, used to determine the 'vertical upright position' (World Athletics Competition Rule 230.1).

Toe-off: The last visible point during stance where the 
athlete's foot clearly contacts the ground.

\subsection{Procedure of Collection of Data}

For kinematic analysis, athletes were recorded as they passed through halfway $(4.55 \mathrm{KM})$ of the race distance on the $400 \mathrm{~m}$ track back straight by using two standard digital HD camcorders (Nikon B700, 60Hz) $90^{\circ}$ angle mounted on rigid tripods $4 \mathrm{~m}$ away from the track inside $\&$ outside where reference volume was $5 \mathrm{~m}$ long and $1.5 \mathrm{~m}$ high. Whereas, to measure $\mathrm{VO}_{2}$ max athletes' performances were taken as they passed through 1.5 miles or $2414.02 \mathrm{~m}$ on the track. The video data were analyzed by using motion analysis software (KINOVEA 0.8.27).

\subsection{Statistical Technique}

Descriptive statistics \& Pearson's product moment correlation coefficient were employed to find the associations of RW performance with the kinematic and physiologic variables. The significance level was set at $95 \%$ of confidence $(p<0.05)$. The tabulation of data was done by using the IBM SPSS 25 software.

\section{Findings and Discussions}

Table 2. Descriptive analysis of kinematic and physiologic variables on elite race walking performance, U-20 Men Junior National Championships.

\begin{tabular}{|c|c|c|c|c|c|}
\hline \multicolumn{6}{|l|}{ Descriptive Statistics } \\
\hline & $\mathbf{N}$ & Minimum & Maximum & Mean & Std. Deviation( $( \pm)$ \\
\hline Ave. velocity (m/s) & 10 & 3.00 & 3.88 & 3.43 & 0.33 \\
\hline Stride length $(\mathrm{cm})$ & 10 & 88.39 & 100.49 & 92.42 & 3.79 \\
\hline Flight distance $(\mathrm{cm})$ & 10 & 11.87 & 29.95 & 22.04 & 6.90 \\
\hline Flight time (sec) & 10 & .05 & .09 & 0.07 & 0.01 \\
\hline Torso displacement $(\mathrm{cm})$ & 10 & 18.62 & 23.92 & 21.09 & 1.78 \\
\hline Pelvic displacement (cm) & 10 & .46 & 3.88 & 1.83 & 1.26 \\
\hline Max. foot height of swing leg $(\mathrm{cm})$ & 10 & 39.00 & 46.92 & 41.49 & 2.31 \\
\hline Max. knee height of swing leg $(\mathrm{cm})$ & 10 & 60.74 & 70.02 & 63.49 & 2.71 \\
\hline Heel contact & 10 & 178.00 & 186.00 & 180.70 & 2.45 \\
\hline Knee angle $\left({ }^{\circ}\right)$ & 10 & 178.00 & 198.00 & 185.60 & 5.52 \\
\hline Toe off & 10 & 145.00 & 154.00 & 150.10 & 2.81 \\
\hline
\end{tabular}

The mean values presented in Table 1 show an average speed of $3.43 \mathrm{~m} / \mathrm{s}$ which paint an exact image how the elite race walkers in the nation stride forward at speeds approaching $12.35 \mathrm{kph}$. The mean aerobic capacity of the race walker which is very relevant with the long distance event $(10 \mathrm{~km})$ found $55.62 \mathrm{ml} \cdot \mathrm{kg}^{-1} \cdot \mathrm{min}^{-1}$. Race walkers were having flight phase with the mean timing of $0.07 \mathrm{sec}$ and average $22.04 \mathrm{~cm}$ flight distance.

Whereas, mean knee angle at heel contact and mid stance phase $180.70^{\circ} \& 185.60^{\circ}$ which show a hyper extended knee that results hindrances in race walk performance as always athletes have to overcome excess angle.

Table 3. Correlation of Race performance with $\mathrm{VO}_{2}$ max.

\begin{tabular}{llll}
\hline Correlations & & & \\
\hline & & Ave. Velocity & $\mathbf{V O}_{2} \mathbf{m a x}$ \\
\hline \multirow{3}{*}{ Ave. velocity } & Pearson Correlation & 1 & $.725^{*}$ \\
& Sig. (2-tailed) & & .018 \\
& $\mathrm{~N}$ & 10 & 10 \\
& Pearson Correlation & $.725^{*}$ & 1 \\
$\mathrm{VO}_{2} \mathrm{Max}$ & Sig. (2-tailed) & .018 & \\
& $\mathrm{~N}$ & 10 & 10 \\
\hline
\end{tabular}

* Correlation is significant at the 0.05 level (2-tailed).

The result of the study showed that the association between race performance and $\mathrm{VO}_{2}$ max was quite high and a significant positive linear relationship found with the performance $(\mathrm{r}$ at $8 \mathrm{df}=0.726)$. Maximum oxygen consumption for top athletes' $60-80 \mathrm{ml} \cdot \mathrm{kg}^{-1} \cdot \mathrm{min}^{-1}$ as compared to untrained people $\left(35-45 \mathrm{ml} \cdot \mathrm{kg}^{-1} \cdot \mathrm{min}^{-1}\right)$ is nearly closer. In a study carried out by Martin et. Al. 2011 [12], showed that race walkers were prevailing average 70 ml.kg ${ }^{-1} \cdot \mathrm{min}^{-1} \mathrm{VO}_{2}$ max that confirms the high maximal oxygen uptake capacity of athlete.

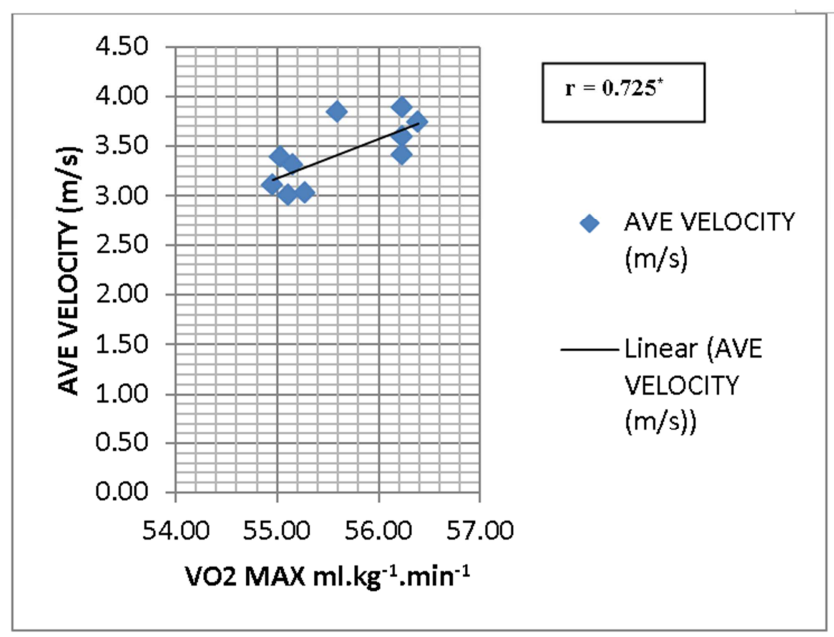

Figure 1. Scatter plotting of Velocity and $\mathrm{VO}_{2}$ Max for top 10 finishers. 
Table 4. Correlation of coefficient of performance with the different kinematic (Linear) variables.

\begin{tabular}{|c|c|c|c|c|c|c|c|c|c|}
\hline \multicolumn{10}{|l|}{ Correlations } \\
\hline & & $\begin{array}{l}\text { Ave. } \\
\text { velocity }\end{array}$ & $\begin{array}{l}\text { Stride } \\
\text { length }\end{array}$ & $\begin{array}{l}\text { Flight } \\
\text { distance }\end{array}$ & $\begin{array}{l}\text { Flight } \\
\text { time }\end{array}$ & $\begin{array}{l}\text { Torso } \\
\text { displacement } \\
\end{array}$ & $\begin{array}{l}\text { Pelvic } \\
\text { displacement }\end{array}$ & $\begin{array}{l}\text { Max. foot height } \\
\text { of swing leg }\end{array}$ & $\begin{array}{l}\text { Max. knee height } \\
\text { of swing leg }\end{array}$ \\
\hline Ave. velocity & Pearson Correlation & 1 & $.693^{*}$ & -.292 & .191 & $.770^{* *}$ & $.804^{* *}$ & .015 & .455 \\
\hline Stride length & Pearson Correlation & $.693^{*}$ & 1 & -.310 & -.048 & .621 & $.861^{* *}$ & -.205 & .304 \\
\hline Flight distance & Pearson Correlation & -.292 & -.310 & 1 & .339 & -.458 & -.197 & -.063 & -.371 \\
\hline Flight time & Pearson Correlation & .191 & -.048 & .339 & 1 & .236 & .141 & .000 & -.088 \\
\hline Torso displacement & Pearson Correlation & $.770^{* *}$ & .621 & -.458 & .236 & 1 & $.796^{* *}$ & .037 & .599 \\
\hline Pelvic displacement & Pearson Correlation & $.804^{* *}$ & $.861^{* *}$ & -.197 & .141 & $.796^{* *}$ & 1 & -.312 & .200 \\
\hline $\begin{array}{l}\text { Max. foot height of } \\
\text { swing leg }\end{array}$ & Pearson Correlation & .015 & -.205 & -.063 & .000 & .037 & -.312 & 1 & .626 \\
\hline Max. knee height of & Pearson Correlation & .455 & .304 & -.371 & -.088 & .599 & .200 & .626 & 1 \\
\hline swing leg & $\mathrm{N}$ & 10 & 10 & 10 & 10 & 10 & 10 & 10 & 10 \\
\hline
\end{tabular}

* Correlation is significant at the 0.05 level (2-tailed).

** Correlation is significant at the 0.01 level (2-tailed).

***Critical value at $8 \mathrm{df} \mathrm{r}=0.632$

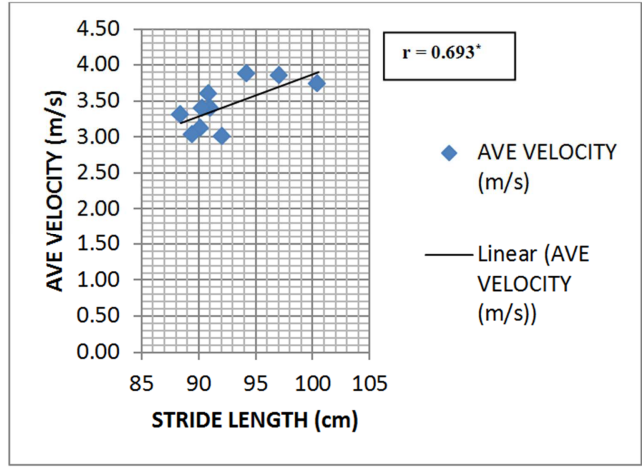

Figure 2. Scatter plotting of Velocity \& Stride length.

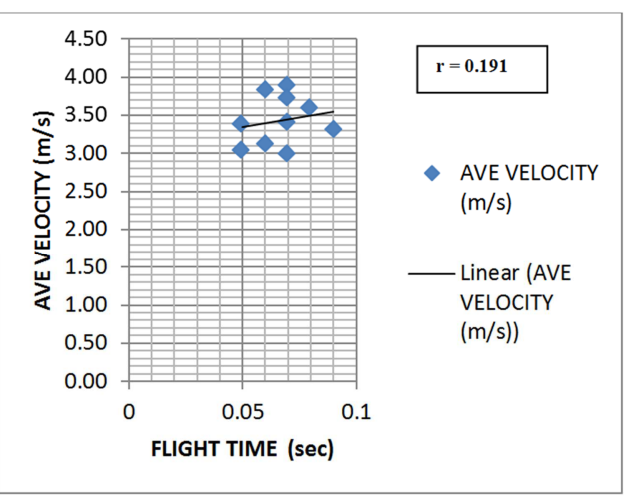

Figure 3. Scatter plotting of Velocity \& Flight time.

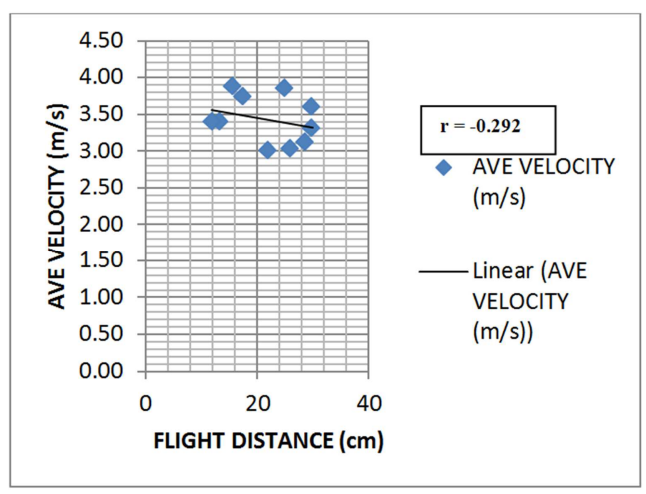

Figure 4. Scatter plotting of Velocity \& Flight distance.

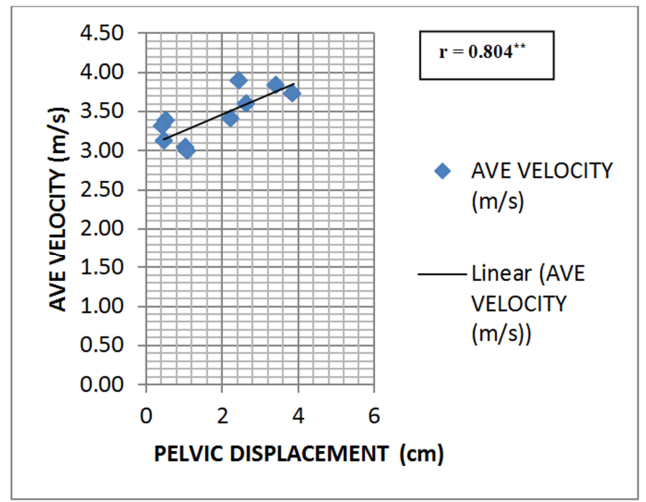

Figure 5. Scatter plotting of Pelvic displacement.

From the above result a strong relationship was found between step length and RW performance, i.e. $\mathrm{r}$ (8df) = 0.689. Stride length is often considered to be the more important and is affected by factors including leg length and the range of movement of the pelvic girdle [8]. Stride frequency is determined by the time taken to complete each successive step, and as a result a shorter step time (usually the result of a shorter contact time) is associated with higher walking speeds [2].

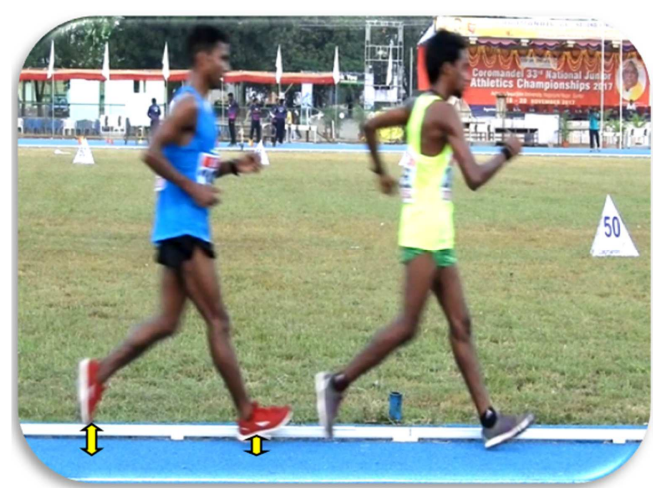

Figure 6. Existence of Swing phase (yellow arrows) with visible loss off contact from the ground found, but not in human eye.

Whereas, variables like, flight time, linearity, maximum knee and foot height of swing leg were positively correlated 
with the walking performance. De Angelis and Menchinelli (1992) ${ }^{3}$ analyzed $14 \mathrm{~km} \cdot \mathrm{h}-1$ (just in the limit of what is perceptible to the human eye). Similarly, Hanley, Bissas, and Drake $(2011)^{5}$ observed flight times of $0.03 \pm 0.01 \mathrm{~s}$ in competition. These results are in line with the values observed in this study $(0.01 \pm 0.07 \mathrm{~s})$, suggesting that worldclass race walkers can compete at fast speeds without a visible loss of contact with the ground (Figure 3). This finding suggests that the most economical race walkers are those exhibiting shorter flight times at a given speed, resulting in a safer race walking technique in terms of risk of disqualification.

A high degree positive association was located in the torso and pelvic displacement $(\mathrm{r}=0.768 \& 0.804)$.

Table 5. Correlation of performance with the Knee angle.

\begin{tabular}{|c|c|c|c|c|c|c|}
\hline & & & \multirow{2}{*}{ Ave. Velocity } & \multicolumn{3}{|l|}{ Knee angel } \\
\hline & & & & Heel contact & Mid stance & Toe off \\
\hline \multirow{2}{*}{\multicolumn{2}{|c|}{ Ave. Velocity }} & Pearson Correlation & 1 & -.491 & -.408 & $.741^{*}$ \\
\hline & & Sig. (2-tailed) & & .150 & .242 & .014 \\
\hline \multirow{4}{*}{$\begin{array}{l}\text { Knee } \\
\text { angle }\end{array}$} & Heel contact & Pearson Correlation & -.491 & 1 & $.893^{* *}$ & -.027 \\
\hline & Mid stance & Pearson Correlation & -.408 & $.893^{* *}$ & 1 & .039 \\
\hline & Toe off & Pearson Correlation & $.741^{*}$ & -.027 & .039 & 1 \\
\hline & & $\mathrm{N}$ & 10 & 10 & 10 & 10 \\
\hline
\end{tabular}

* Correlation is significant at the 0.05 level (2-tailed).

** Correlation is significant at the 0.01 level (2-tailed).

$* * *$ Critical value at $8 \mathrm{df} r=0.632$

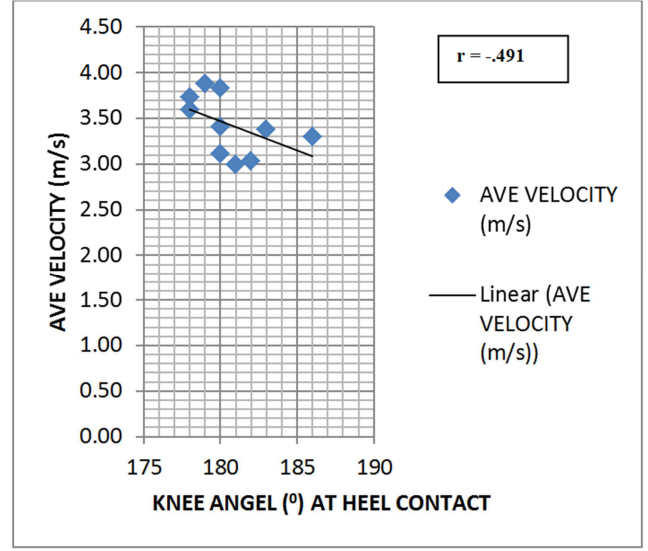

Figure 7. Scatter plotting of knee angel during Heel contact.

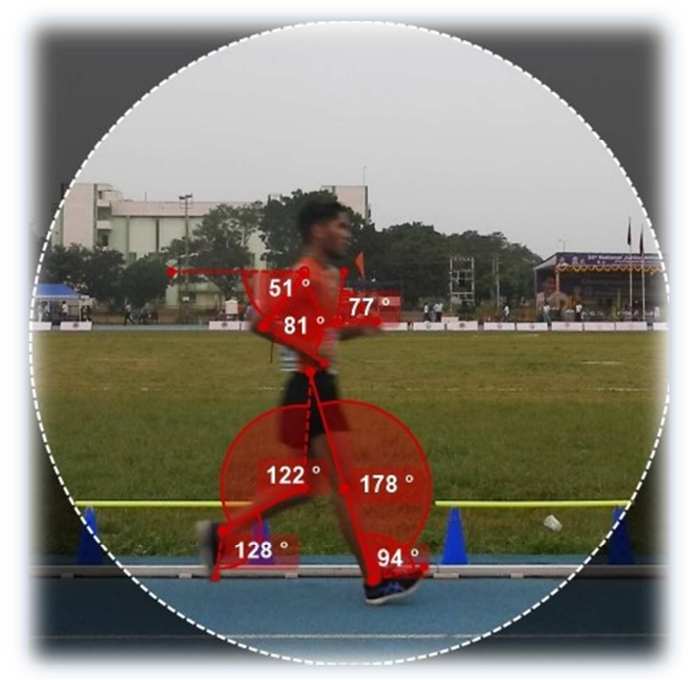

Figure 8. Angular measure of different joints.

Table 5 shows a high degree coefficient of correlation in toe off phase $(r=0.742)$ between knee angle \& RW performance. Whereas at heel contact and mid stance phase a low degree negative correlation found $(r=-0.489 \&$ 0.406). High degree positive relationship found in ankle angle in heel contact other than rest two phases i.e. $r=$ 0.637 . Most of the calculated " $r$ " values were significant as the critical value of $8 \mathrm{df}$ at 0.05 level is 0.631 . Due to the direct association of race walking velocity with $\mathrm{VO}_{2}$ max, step length, knee angle, torso \& pelvic displacement may be this type of result found in different phases. There is a direct link between the position of the foot and the joint angles of the entire leg. First, the hip angle will determine how far in front or behind the body the foot is placed. Increasing hip extension velocity results in a decrease in support time, which in turn allows for much longer strides to be taken [10]. Second, the knee is in many regards the most important joint to analyze during race walking as it is the only joint to which specific technical rules are applied. Although an extended knee is abnormal during normal walking or running, research has shown that a straight knee at landing is of benefit to race walkers [2]. Finally, the angle of the ankle at different points in the support phase is important: at initial contact for ensuring a straightened knee and at toe-off as its plantar-flexion aids the drive phase of the step [16]. But, the relationships of some kinematic variable with the race walking performance were very much closer to be significantly significant.

\section{Conclusions}

In summary, race walking performance was positively associated with the race walking economy (kinematic and physiologic variables), which implies that the fastest race walkers were more economical than the lesser performers. In relation to RW technique and forward propulsion, displacement of torso and pelvic region observe a significant role. Similarly, race walking performance and technique were related to joints angel at the different phases of gait cycle (Support phase i.e. Heel contact, Mid stance \& Toe off) and swing time, which highlights the importance of race walking 
biomechanics for elite competitors in this sport. In this regard, shorter flight times (below of what is perceptible for the human eye) and longer flight distance may reduce the aerobic capacity of race walking in world-class race walkers. Since the rules of the sport penalize a visible lost of contact with the ground, coaches and race walkers should avoid modifying their race walking style by increasing flight times, as it may not only impair economy, but also lead to disqualification.

\section{Acknowledgements}

Author thanks Professor Brajanath Kundu for his continuous guidance; DPESS, Visva-Bharati University, India for creating the platform of research work; West Bengal Athletic Association, Athletic Federation of India, Acharya Nagarjuna University Athletic coach and MPED students for their assistance with data collection, data analysis, and/or animal care. Finally, I would like to acknowledge intellectual and technical support from Mr. Subhash Nandi, Mr. Sanjay Ghosh, Dr. Sahidul Hamid, and Mr. Ujjwal Das Roychoudhury. This work was supported by the Athletic Federation of India. The content is solely the responsibility of the authors.

\section{Authors' Contributions}

Authors were responsible for the study conceptualization, methodology development, validation, formal analysis manuscript writing (preparation and editing), data visualization, study supervision, funding acquisition, formal analysis, writing (preparation and editing), and data visualization. All authors have read and approved the final version of the manuscript, and agree with the order of presentation of the authors.

\section{Competing Interests}

The authors declare that they have no competing interests.

\section{References}

[1] Brisswalter, J.; Fougeron, B., \& Legros, P. (1998). Variability in energy cost and walking gait during race walking in competitive race walkers, Medicine and Science in Sport and Exercise, 30 (9): 1451-1455.

[2] Cairns, M.; Burdette, R.; Pisciotta, J., \& Simon, S. (1986). A biomechanical analysis of racewalking gait, Medicine and Science in Sport and Exercise, 18 (4): 446-453.
[3] De Angelis, M., \& Menchinelli, C. (1992). Times of flight, frequency and length of stride in race walking. In R. Rodano (ed.), Proceedings of the $\mathrm{X}$ international symposium of biomechanics in sports. Milan, Italy.

[4] Hanley, B., \& Bissas, A. (2017). Analysis of lower limb workenergy patterns in world-class race walkers. Journal of Sports Sciences, 35 (10), 1-7.

[5] Hanley, B.; Bissas, A. \& Drake, A. (2011). Kinematic characteristics of elite men's and women's $20 \mathrm{~km}$ race walking and their variation during the race. Sports Biomechanics, 10 (2): $110-124$.

[6] Hanley, B.; Bissas, A. \& Drake, A. (2013). Kinematic characteristics of elite men's $50 \mathrm{~km}$ race walking. European Journal of Sport Science, 13 (3): 272-279.

[7] Hanley, B.; Bissas, A. (2012). Differences between body segment parameter models in analysing elite race walkers in competition, Gazzetta Medicaitaliana, 171 (5): 541-550.

[8] Hoga, K., Ae, M., Enomoto, Y. Fujii, N. (2003) Mechanical energy flow in the recovery leg of elite race walkers. Sports Biomechanics, 2 (1), 1-13. 3 (1) 53-59.

[9] Hopkins, W., Marshall, S., Batterham, A., \& Hanin, J. (2009). Progressive statistics for studies in sports medicine and exercise science. Medicine \& Science in Sports \& Exercise, $41(1), 3$.

[10] Lafortune, M., Cochrane, A., \& Wright, A. (1989). Selected biomechanical parameters of race walking. Excel, 5, 15-17.

[11] Larsen GE, George JD, Alexander JL, Fellingham GW, Aldana SG \& Parcell AC. Prediction of Maximum Oxygen Consumption from Walking, Jogging, or Running. Research Quaterly for Exercise and Sports Journal. 2002; Vol-73, Issue1: 66-72.

[12] Martin et. al. (2011). Dependence between anaerobic threshold and maximum oxygen consumption in race walker. World race walking research. 26-29.

[13] Payne, H., and Payne, R. (1981) Walks. In Payne, H. and Payne, R. (Eds.) The science of track and field athletic.

[14] Salvage, J., Bolwicaski, B., Robertson, G., Whatley, I., and Westerfield, G. (2000) Race Walking. In Hambly, L. (Eds.) USA Track \& field coaching manual. Human kinetics, Champain, Illinois, pp. 281-286.

[15] Summers, H. (1991). Placement of the leading foot in race walking. Modern Athlete and Coach, 29 (1), 33-35.

[16] White, S. C. \& Winter, D. (1985). Mechanical power analysis of the lower limb musculature in race walking, International Journal of Sport Biomechanics, 1 (1): 15-24.

[17] World Athletics (International Association of Athletics Federation, IAAF). Competition rules 2017. www.worldathletics.org. Competitions and technical rules 2020. 